\title{
Laser Surface Modification of Ti6Al4V-Cu for Improved Microhardness and Wear Resistance Properties
}

\author{
Mutiu Folorunsho Erinosho ${ }^{a *}$, Esther Titilayo Akinlabi ${ }^{a}$, Sisa Pityana ${ }^{b}$, Gbadebo Owolabi ${ }^{c}$ \\ ${ }^{a}$ Department of Mechanical Engineering Science, University of Johannesburg, Auckland Park \\ Kingsway Campus, Johannesburg, 2006, South Africa \\ ${ }^{b}$ Council for Scientific and Industrial Research, National Laser Centre, PO Box 375, Pretoria, 0001, \\ South Africa \\ ${ }^{c}$ Mechanical Engineering, Howard University, $23006^{\text {th }}$ Street NW, Washington DC, 20059, USA
}

Received: February 03, 2017; Revised: May 02, 2017; Accepted: May 27, 2017

\begin{abstract}
To modify the properties of Ti6Al4V alloy, $\mathrm{Cu}$ has been added to host an antimicrobial effect in the revised alloy for marine application. The Laser Metal Deposition (LMD) process on the Ti6Al4V alloy and $\mathrm{Cu}$ was been investigated for surface modification in order to combat the problem of biofouling in the marine industry. The investigations focused on the microstructural observations, micro-hardness measurements and dry sliding wear in the presence of 3 and 5 weight percents of $\mathrm{Cu}$. The microstructure results showed that Widmanstätten microstructures were formed in all the samples and lose their robustness towards the fusion zone as a result of the transition of heat sink towards the substrate. The microhardness values of Ti6Al4V-3Cu and Ti6Al4V-5Cu alloys were greatly improved to $547 \pm 16 \mathrm{VHN}_{0.5}$ and $519 \pm 54 \mathrm{VHN}_{0.5}$ respectively. Furthermore, the behaviour of wear loss on the surface of the Ti6Al4V-Cu alloys exhibited great improvement as compared with the parent material.
\end{abstract}

Keywords: dry sliding wear, laser metal deposition, microstructure, micro-hardness measurements, Ti6Al4V-Cu alloy, wear loss

\section{Introduction}

Titanium and its alloys are amongst the most important alloys of the advanced materials which are the key to improving performance in the aerospace and terrestrial systems ${ }^{1-3}$. The improvements in mechanical properties of the titanium alloys have generally been accomplished through the addition alloying compound ${ }^{4-7}$. The alloying additions in titanium can be divided into three different classes. The $\alpha$-stabilizers such as Aluminium which impact solid solution strengthening to titanium; the $\beta$-stabilizers such as copper, chromium, vanadium, iron, niobium, molybdenum and manganese. They serve to introduce the $\beta$-phase in the $\alpha$-phase microstructural counterpart; and the neutral additions such as tin and zirconium also contribute towards solid solution strengthening ${ }^{8}$. According to the structural alloy hand book, most of these alloys have found restricted use in the mechanical engineering applications due to their poor abrasive wear resistance, high coefficient of friction and the fretting characteristics. These anomalies behaviour of titanium alloys could be enhanced and modified by treating the surfaces with coatings9. Four main mechanisms have been stipulated to improve the wear behaviour of titanium alloys and these are: increase in the hardness, inducing compressive residual stress, reduction in the coefficient of friction and increase in the surface roughness ${ }^{10}$. Titanium nitride has been coated on copper and brass substrates

* e-mail: mutiuerinosho1@gmail.com with an electroless nickel interlayers. The hardness of the composite was increased with the electroless nickel interlayer thickness. The coefficient of friction was also increased with an increase in the thickness of electroless nickel interlayer for both copper and brass substrates ${ }^{11}$. The wear behaviour of teeth was evaluated with cast titanium alloys containing 3 weight percent of copper, 5 weight percent of copper and Ti6Al4V alloy containing 1 weight percent of copper and 4 weight percent of copper. Their results were compared with commercially pure (CP) titanium, Ti6Al4V alloy and gold alloy. The wear resistance of the CP Ti and Ti6Al4V with copper addition $\mathrm{Cu}$ were found to show better wear properties than the Ti and Ti6A14V alloy. Gold alloy was also presented to have the best wear property. Conclusion was made that wear resistance was improved with the copper alloying and with the introduction of $\mathrm{Ti} / \mathrm{Ti}_{2} \mathrm{Cu}$ eutectoid ${ }^{12}$. The framework of this research work originates with an overview of the contingent works that have been carried out by famous authors and researchers from perspective and area of specialisation. Biofouling is a major dilemma for many materials when exposed to chemically aggressive sea water ${ }^{13}$. It is the growth of micro-organisms at the interface of metal ${ }^{14}$, and this problem has caused an increase in maintenance, fuel and downtime costs to the shipping industry ${ }^{15} .10 \mathrm{wt}$ $\%$ of $\mathrm{Cu}$ was added to $\mathrm{Al}$ and $\mathrm{Ti}$, and the resulting sample is subjected to corrosion test in natural sea water. The presence of $\mathrm{Cu}$ improved the corrosion resistance of $\mathrm{Al}$, and however, 
the addition of $5 \mathrm{wt} \% \mathrm{Ti}$ also enhanced the passivation and good corrosion rate ${ }^{16}$. It was found that alloys containing $60-70 \% \mathrm{Cu}$ content attack marine growth. However, this $\mathrm{Cu}$ can be used in anodic production to form $\mathrm{Cu}$ ions $\left(\mathrm{Cu}^{2+}\right)$ during oxidation. This is of high toxicity, and is effective for destroying the marine organisms. An investigation was conducted using copper-sulphate solution in a reversible reaction; and this proved that the $\mathrm{Cu}^{2+}$ reduces both macroand micro-biological fouling ${ }^{17}$. In this present work, $\mathrm{Cu}$ has been selected due to its antimicrobial property, and in addition, it is a naturally hygienic metal, which retards the growth of harmful germs. These properties have thus, made it ideal for brewing vessels ${ }^{18}$. Several anti-biofouling agencies such as chemical, biological and mechanical methods are in practice but their effects are not significant. Natural source antifouls are considered as one of the best replacement options for the antifouling processes ${ }^{19}$. However, the motivation for this work is to modify and improve the surface of Ti6Al4V alloy with the addition of $\mathrm{Cu}$ for better microhardness and wear resistance properties through the laser metal deposition (LMD) process for marine application. The novelty of this work is the introduction of 3 weight percent (wt \%) of $\mathrm{Cu}$ to titanium alloy (Ti6Al4V-3Cu) and 5 wt $\%$ of $\mathrm{Cu}$ to Ti6Al4V alloy (Ti6Al4V-5Cu) respectively, for the purpose of reducing the problem of biofouling in the marine industries. The parameters used in this study were selected from the preliminary studies and the chosen deposited Ti6Al4V-Cu alloys for characterization were of good bonding and surface roughness.

\section{Experimental Structure and Techniques}

The main laser deposition experiment was conducted at the Council of Scientific and Industrial Research, Pretoria, South Africa, CSIR. The equipment used was Ytterbium fiber laser system equipment (YLS-2000-TR) and function at a maximum power of $2 \mathrm{~kW}$. Figure 1 shows a typical Kuka robot with a nozzle attached to the laser head performing LMD operation.

Two powders used for this research were Ti6Al4V and $\mathrm{Cu}$ powders and having particle sizes varying between 100 and $200 \mu \mathrm{m}$. The two powders were fed from two different hoppers and their flows were assisted with the aid of an argon

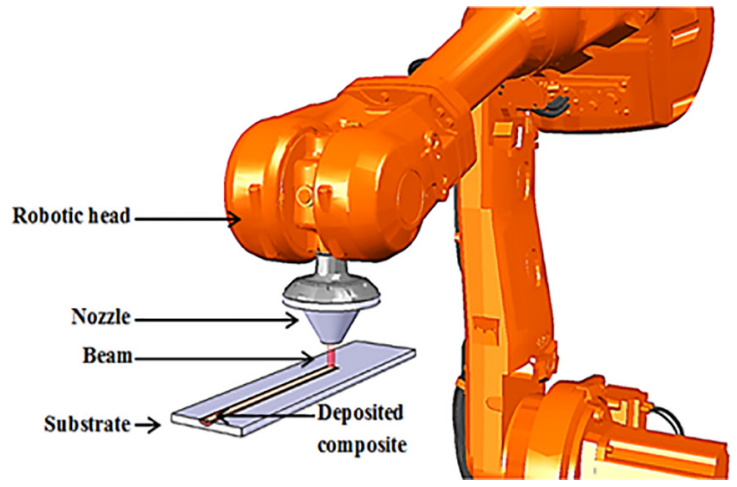

Figure 1. Typical Kuka robot.

gas (carrier gas). The argon gas was also supplied to provide a shield during the deposition to prevent oxygen contamination on the deposited alloys. A $99.6 \%$ solid rectangular plate of Ti6Al4V alloy dimensioned with $\left(102\right.$ X 102 X 7.45) $\mathrm{mm}^{3}$ was used as the substrate. The substrate was grit-blasted prior to deposition to remove surface contaminants and to prepare the surface for firm metallographic bonding between the alloys formed. Table 1 depicts the process parameters used for the experiment.

The beam diameter, the track length and the standoff distance were set at $4 \mathrm{~mm}, 5 \mathrm{~mm}$ and $12 \mathrm{~mm}$ respectively. All the samples were prepared following the procedures of grinding, polishing and etching according to E3-11 ASTM standard ${ }^{20}$.

\subsection{Microstructure}

According to the guidelines listed in the Struers application note of metallurgical preparation of titanium, the Kroll's reagent was prepared for the etchant with $\left(100 \mathrm{ml} \mathrm{H}_{2} \mathrm{O}, 2-3\right.$ $\mathrm{ml} \mathrm{HF}$ and 4-6 $\left.\mathrm{ml} \mathrm{HNO}_{3}\right)^{21}$. Each sample was etched for 10 -15 seconds, cleaned with ethanol, rinsed under running water and dried off prior to Scanning Electron Microscope (SEM) and optical microscopic (OM) observations. The SEM was conducted on the samples using the TESCAN instrument with Vega TC software to run the analysis. The machine is equipped with an X-MAX instrument, and with an Electron Dispersive Spectroscopy (EDS), using INCA-point ID software. The SEM analysis was carried out on the Ti6Al4V

Table 1. Experimental matrix

\begin{tabular}{|c|c|c|c|c|c|c|c|}
\hline \multirow{2}{*}{ Sample Name } & \multirow{2}{*}{$\begin{array}{l}\text { Laser Power } \\
\text { (W) }\end{array}$} & \multirow{2}{*}{$\begin{array}{c}\text { Scanning } \\
\text { Speed } \\
(\mathrm{m} / \mathrm{min})\end{array}$} & \multirow{2}{*}{$\begin{array}{c}\text { Copper Wt.\% } \\
(\%)\end{array}$} & \multicolumn{2}{|c|}{ Powder Flow rate (rpm) } & \multicolumn{2}{|c|}{ Gas Flow rate $(1 / \mathrm{min})$} \\
\hline & & & & Ti6Al4V & $\mathrm{Cu}$ & Ti6Al4V & $\mathrm{Cu}$ \\
\hline $\mathrm{Z1}$ & 1200 & 0.7 & 5 & 2.4 & 0.1 & 3 & 1 \\
\hline $\mathrm{Z} 2$ & 1600 & 0.3 & 3 & 2.5 & 0.1 & 3 & 1 \\
\hline $\mathrm{Z3}$ & 1200 & 0.3 & 5 & 2.4 & 0.1 & 3 & 1 \\
\hline $\mathrm{Z} 4$ & 1400 & 0.3 & 5 & 2.4 & 0.1 & 3 & 1 \\
\hline $\mathrm{Z5}$ & 1600 & 0.3 & 5 & 2.4 & 0.1 & 3 & 1 \\
\hline Ti6Al4V & 1600 & 0.3 & 0 & 2.4 & Nil & 3 & Nil \\
\hline
\end{tabular}


and $\mathrm{Cu}$ powders. Figures $2 \mathrm{a}-\mathrm{b}$ show the morphologies of Ti6Al4V and $\mathrm{Cu}$ powders.

The morphologies of both the Ti6Al4V and $\mathrm{Cu}$ powders were spherical in shape. The particle size of Ti6Al4V was observed to be equiaxed and the surfaces were smooth with satellites (dust particles) agglomerated scantily to the bigger particles. The particle sizes of $\mathrm{Cu}$ were also observed to be equiaxed in morphology and showed denser and immense faces compared to Ti6Al4V alloy powders.

\subsection{Hardness test}

Microhardness tests were performed on both the cross section and the surface of the substrate; and each of the deposited Ti6A14V-Cu alloys on a Vickers hardness machine Zwick/Roell. A load of $500 \mathrm{~g}$ and a dwell time of 15 seconds were used throughout the hardness test according E384 -11e1 ASTM standard ${ }^{22}$.

\subsection{Wear test and wear loss characterization}

The dry sliding wear tests were conducted on a micro tribometer module, CETR UTM-2 operating with linear reciprocating motion drive. The samples are rubbed against a ball-shaped upper specimen made of $9.5 \mathrm{~mm}$ diameter tungsten carbide ball. A load of $25 \mathrm{~N}$, stroke length of 2 $\mathrm{mm}$, oscillation frequency of $5 \mathrm{~Hz}$ and test duration of 1000 seconds were selected for the operation. The dry sliding wear tests were carried out according to the ASTM G13305 for determining the sliding wear of metals ${ }^{23}$. The wear loss was calculated from the length of the stroke, the width of the wear scar and the depth of wear (groove) that were

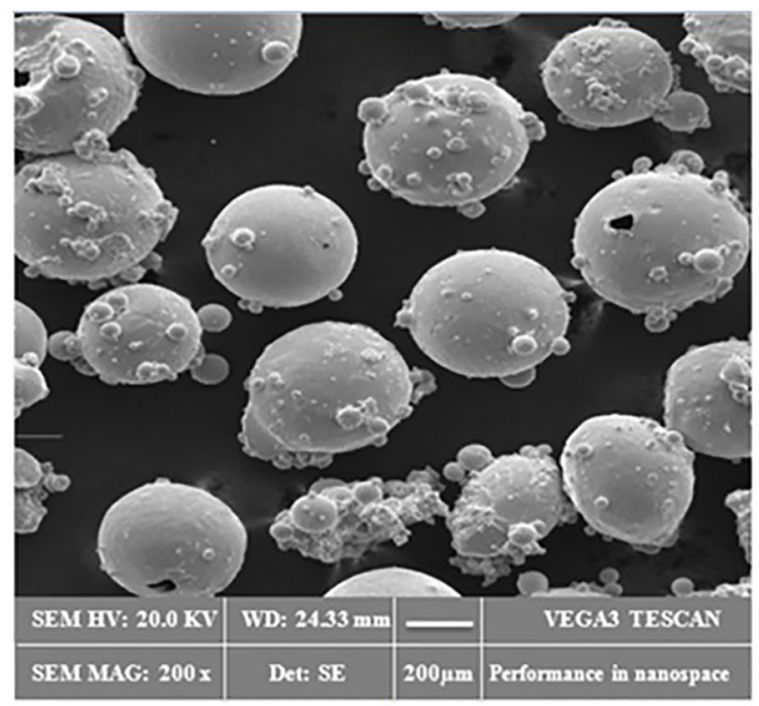

(a) made on the surface of the deposited samples as shown in equations (1) and (2) ${ }^{24}$.

$$
\begin{aligned}
& V_{l}=L_{s}\left[R_{p}^{2} \sin ^{-1}\left(\frac{W}{2 R_{p}}\right)-\frac{W}{2}\left(R_{p}-W_{d}\right)\right]+ \\
& \frac{\pi}{3} W_{d}^{2}\left(3 R_{p}-W_{d}\right) \\
& W_{d}=R_{p}-\sqrt{R_{p}^{2}-\frac{W^{2}}{4}}
\end{aligned}
$$

Where $V_{1}$ is the wear loss; $L_{s}$ is the stroke length; $R_{p}$ is the pitch radius; $\mathrm{W}$ is width of the wear scar and $\mathrm{W}_{\mathrm{d}}$ represents the wear depth.

\section{Results and Discussions}

\subsection{Microstructural analysis}

The SEM analysis of the surface and the cross section of the parent material were characterised and the microstructures are shown in Figures 3 a-b.

The microstructures show the -phase in the dark region and the -phase in the white region. The grain boundaries of the -phases are more pronounced and thicker that the -phases as observed in Figure 3a. Figure 3b shows the cross sectional view of the bulk material. The grain boundaries were observed to be elongated and this shows that the material is a rolled material. The macrographs of the etched deposited Ti6Al4V-Cu alloy samples are illustrated in Figure 4. All the selected samples from the preliminaries are well bonded to the substrate with no porosities. Figures $4 \mathrm{a}-\mathrm{d}$ show the macrographs of the etched composites of samples Z2, Z3, $\mathrm{Z} 4$ and $\mathrm{Z} 5$ respectively.

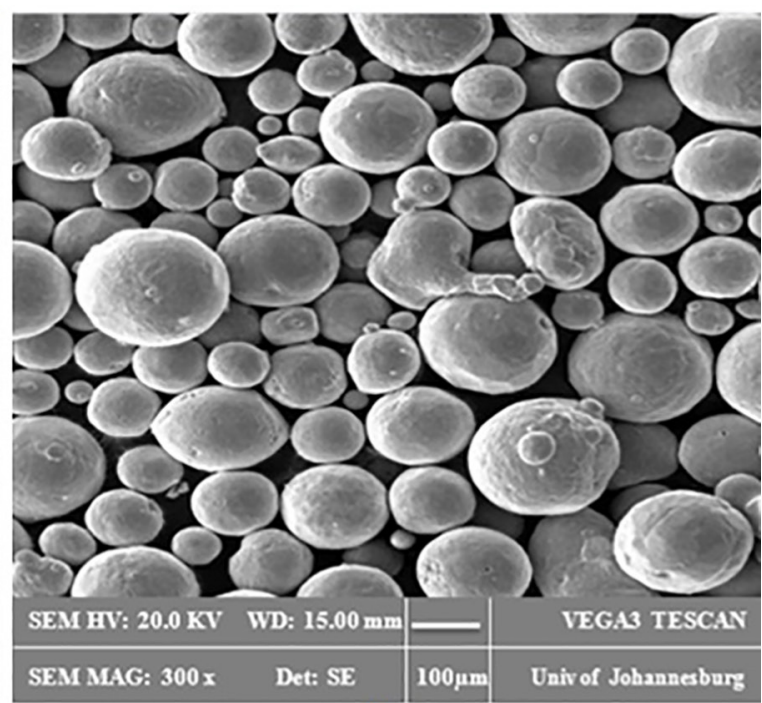

(b)

Figure 2. SEM morphologies (a) Ti6Al4V powder; (b) Cu powder. 


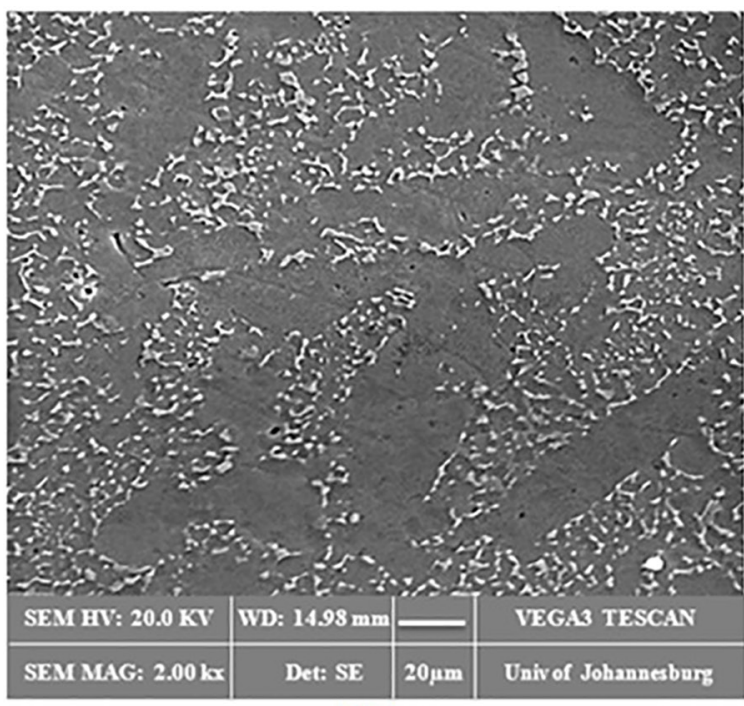

(a)

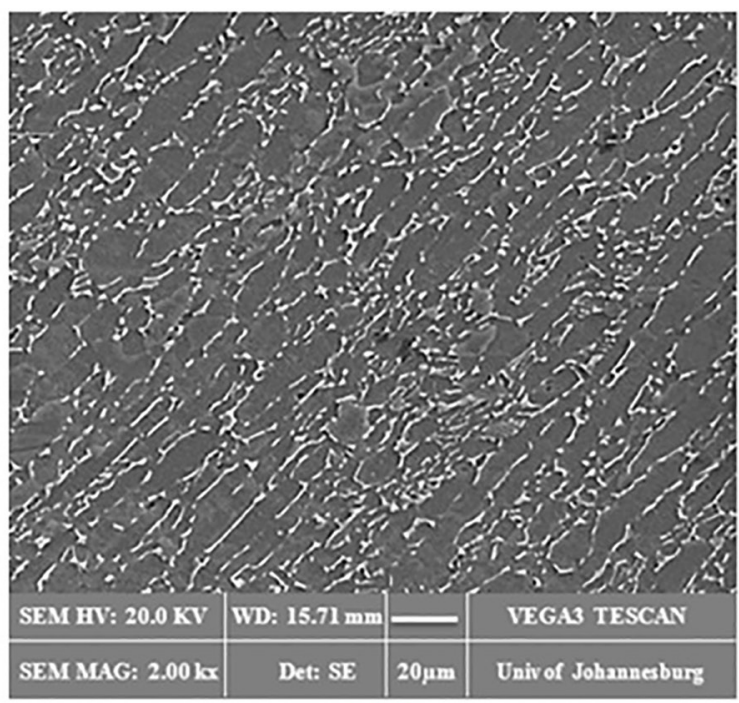

(b)

Figure 3. SEM micrographs of the substrate (a) Surface; (b) Cross section.
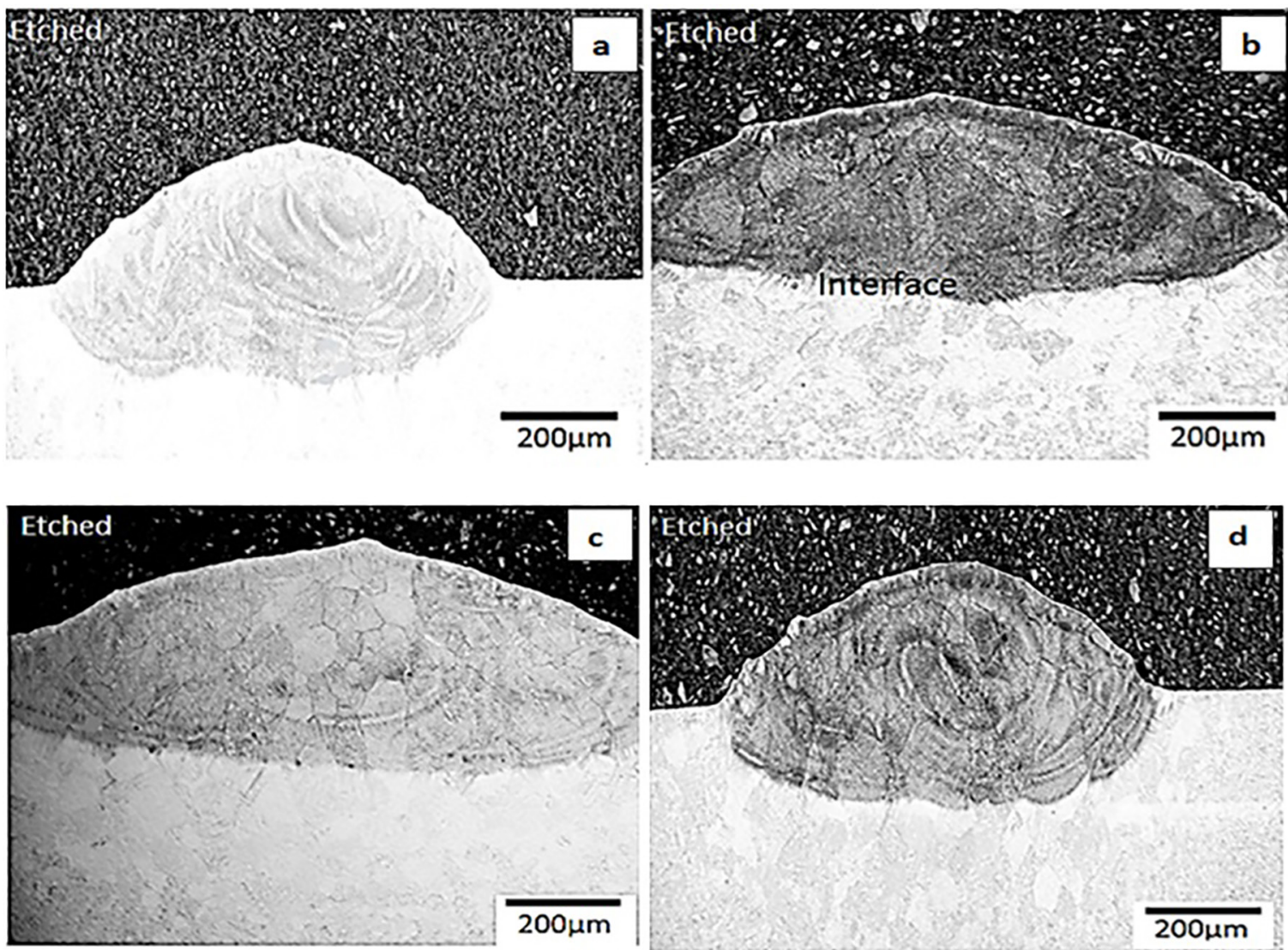

Figure 4. Macrographs of the etched Ti6Al4V-3Cu and Ti6Al4V-5Cu alloys deposited at various process parameters, (a) Sample Z2 with 3 wt \% Cu: 1600 W, 0.3 m/min and 2.5 rpm; (b) Sample Z3 with 5 wt \% Cu: 1200 W, $0.3 \mathrm{~m} / \mathrm{min}$ and $2.4 \mathrm{rpm}$; (c) Sample Z4 with 5 wt $\% \mathrm{Cu}: 1400 \mathrm{~W}, 0.3 \mathrm{~m} / \mathrm{min}$ and $2.4 \mathrm{rpm}$; (d) Sample Z5 with $5 \mathrm{wt} \% \mathrm{Cu}: 1600 \mathrm{~W}, 0.3 \mathrm{~m} / \mathrm{min}$ and $2.4 \mathrm{rpm}$. 
The microstructures of the selected Ti6Al4V-3Cu and Ti6Al4V-5Cu alloys observed by SEM and Optical microscope (OM) are presented Figure 5.

The SEM analysis of sample Z1 of Ti6Al4V-5Cu alloy deposited with a laser power of $1200 \mathrm{~W}$ and scanning speed of $0.7 \mathrm{~m} / \mathrm{min}$ is described in Figures $5 \mathrm{a}-\mathrm{b}$ with the Figure 5a showing the top view of the deposited alloy with the dominance of Widmanstätten structures. Figure $5 \mathrm{~b}$ shows the middle view and the fusion zone (FZ) of the alloy. Here, the Widmanstätten structures were observed to be thinner towards to the FZ; and this was as a result of the heat sink that exists between the deposit and the substrate. Figures 5 c-d show the SEM analyses of sample Z2 of Ti6Al4V-3Cu alloy deposited with a laser power, a scanning speed and a powder flow rate of $1600 \mathrm{~W}, 0.3 \mathrm{~m} / \mathrm{min}$ and $2.5 \mathrm{rpm}$; and sample Z3 of Ti6Al4V-5Cu alloy deposited with a laser power and a scanning speed of $1200 \mathrm{~W}$ and $0.3 \mathrm{~m} / \mathrm{min}$; and their EDS analyses at the regions indicated by arrows. The black spots observed within the Widmanstätten structures were assumed to be oxides of titanium alloy. Figure 5e shows the microstructural analysis of sample $\mathrm{Z} 2$ of Ti6A14V-3Cu alloy (deposited with a laser power and a scanning speed of $1600 \mathrm{~W}$ and $0.3 \mathrm{~m} / \mathrm{min}$ ) towards the top of the deposited alloy. Numerous erected, symmetrical and thick feathers-like microstructures were observed protruding from the grain boundaries and were elongated towards the top of the deposit of sample Z2. Figure $5 \mathrm{f}$ shows the OM analysis towards the substrate of sample Z3 of Ti6A14V-5Cu alloy. Widmanstätten structures were observed in most of the microstructures and their textures are dependent on the process parameters used. The -Ti phases were found to hinder the continuous flow (plastic deformation) of the -phase during cooling due to variation in the slip system. During this process, macroscopic banding is developed between the boundaries. Sample Z4 of Ti6Al4V-5Cu deposited with a laser power of $1400 \mathrm{~W}$, a scanning speed of $0.3 \mathrm{~m} / \mathrm{min}$ and powder flow rate of $2.4 \mathrm{rpm}$ shows some backbone-like microstructure. The backbone-like structures were formed towards the top at an angle approximately $60^{\circ}$ to the horizontal. -Ti lamella was observed in gradient bundles between the backbone-like structures and the Widmanstätten structures.

\subsection{The microhardness evaluation}

The microhardness evaluation of the substrate and the deposited Ti6Al4V-Cu alloys are presented and discussed. Figure 6 displays the histogram plot of the microhardness values of the substrate (surface and cross section), Ti6Al4V alloy, Ti6Al4V-Cu, Ti6Al4V-3Cu and Ti6Al4V-5Cu alloys respectively.

The addition of $\mathrm{Cu}$ has greatly improved the microhardness values of Ti6Al4V alloy even though the hardness value of Ti6Al4V alloy was higher than 1 weight percent of $\mathrm{Cu}$ in Ti6Al4V-Cu alloy. The average microhardness values obtained for the laser deposited Ti6Al4V alloy, Ti6Al4V-Cu, Ti6Al4V$3 \mathrm{Cu}$, and Ti6Al4V-5Cu are $444 \pm 49 \mathrm{VHN}_{0.5}, 397 \pm 56 \mathrm{VHN}_{0.5}$, $547 \pm 16 \mathrm{VHN}_{0.5}$, and $519 \pm 54 \mathrm{VHN}_{0.5}$ respectively. The hardness measurements were conducted from the top of the deposit to the substrate and thereby solving for their average hardness values. Aoki et al. ${ }^{25}$ improved the mechanical properties of cast Ti6Al4V alloy with the addition of (1 and 4) wt \% Cu. Their hardness values were much improved as compared to the Ti6Al4V alloy ${ }^{25}$. It was so interesting that the hardness of the alloys with $5 \mathrm{wt} \%$ of $\mathrm{Cu}$ was lower than that of the 3 wt $\%$ of $\mathrm{Cu}$. However, it can also be construed that the density of Ti6Al4V-Cu alloys increases with an increase in $\mathrm{Cu}$ content. Ma et al. ${ }^{26}$ reported that a high density boundary generates more plastic deformation that led to a decrease in material hardness ${ }^{26}$. Ti6Al4V alloy powder was deposited on the substrate at a laser power of $1600 \mathrm{~W}$ and scanning speed of $0.3 \mathrm{~m} / \mathrm{min}$, and however its hardness values were measured in order to check for the hardness variation with that of the rolled Ti6Al4V alloy substrate. Thus, from the histogram plot, it was discovered that the hardness value of the laser deposited Ti6Al4V sample is more than the hardness value of the substrate (on both the surface and the cross section). This phenomenon is attributed to the heating and cooling effect of the laser beam on the deposit. Thus, laser deposited Ti6A14V alloy has a strong effect on the hardness value compare with the rolled counterpart.

\subsection{Tribological testing and the wear analyses}

The results of the wear test conducted on the surfaces of the deposited alloys are presented and analysed. The back and forth movement of the tungsten carbide ball over the alloy's surfaces has induced a wear ridge on them due to the high hardness of the wearing ball. An abrasive wear takes place between the carbide ball and the composites. Figures 7 a-d show the SEM micrographs of the worn surfaces of the substrate, Ti6A14V alloy deposited at a laser power of 1600 $\mathrm{W}$ and scanning speed $0.3 \mathrm{~m} / \mathrm{min}$, Ti6Al4V-3Cu deposited at a laser power of $1600 \mathrm{~W}$ and scanning speed $0.3 \mathrm{~m} / \mathrm{min}$ and Ti6A14V-5Cu deposited at a laser power of $1200 \mathrm{~W}$ and scanning speed $0.3 \mathrm{~m} / \mathrm{min}$ respectively.

The ellipse signs indicate the region of the wear groove and showed the level at which the surface is worn. It was very surprising that the substrate in Figure 7a shows the widest in wear width and lowest in wear depth. The occurrence could be due to the compressive nature of the grain boundaries and the rolled nature of the substrate. The wear depth is always given by the software through the computer of the wear equipment. The wear width is always measured using the SEM. The substrate is a rolled material made of $99.6 \%$ Ti6Al4V alloy. The worn surface of laser deposited Ti6Al4V alloy presented in Figure 7b is a deposition with Ti6A14V alloy powder which was conducted by laser deposition process. This was done to compare the result with laser deposited 

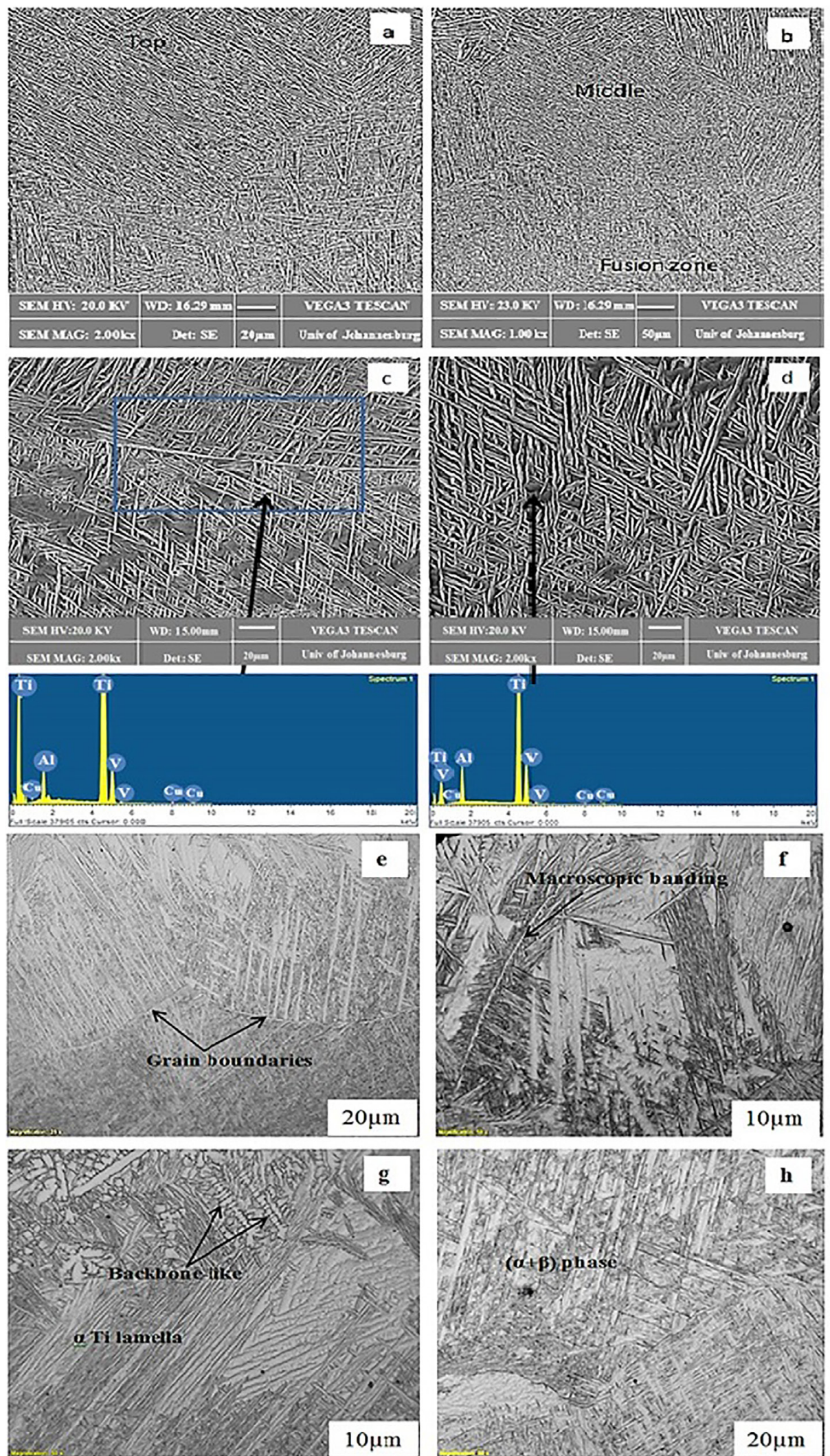

Figure 5. SEM and OM analyses of the selected Ti6Al4V-3Cu and Ti6Al4V-5Cu composites: (a and b) SEM analyses of sample $\mathrm{Z1}$ showing the top view, the middle view and the fusion zone; (c and d) SEM analyses of sample Z2 deposited at $1600 \mathrm{~W}, 0.3 \mathrm{~m} / \mathrm{min}$ and $2.5 \mathrm{rpm}$, and sample $\mathrm{Z} 3$ deposited at $1200 \mathrm{~W}$ and $0.3 \mathrm{~m} /$ min; (e) OM analysis showing the top view of sample Z2; (f) OM analysis towards the substrate of sample Z3 deposited at $1200 \mathrm{~W}$ and $0.3 \mathrm{~m} / \mathrm{min}$; (g) OM analysis of sample $\mathrm{Z} 4$ deposited at $1400 \mathrm{~W}$ and $0.3 \mathrm{~m} / \mathrm{min}$; (h) OM analysis of sample Z5 deposited at $1600 \mathrm{~W}, 0.3 \mathrm{~m} / \mathrm{min}$ and $2.4 \mathrm{rpm}$. 


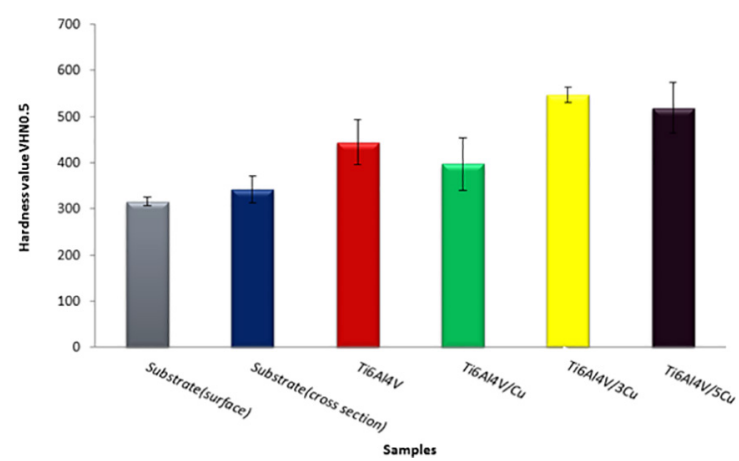

Figure 6. Plot of microhardness of the substrate, Ti6A14V alloy, Ti6Al4V-Cu, Ti6Al4V-3Cu and Ti6Al4V-5Cu alloys.

Ti6Al4V-Cu alloy. The different production processes of the rolled substrate and the laser deposited Ti6A14V alloy have significant effect on their results. The size of ellipse sign was reduced for Ti6Al4V-Cu composites and this could be attributed to the $\mathrm{Cu}$ inclusion and the surface roughness of the composites. Figures 8 a-d show the SEM micrographs of the wear debris of the substrate, Ti6Al4V alloy, Ti6Al4V-3Cu and Ti6Al4V-5Cu alloys under the load of $25 \mathrm{~N}$.

The wear tracks disclosed the ridges and grooves parallel to the sliding direction of the tungsten ball. The SEM micrograph of the substrate shows the roughness of the ploughs and follows the direction of the slide. Wear debris were observed in between the ridges and found agglomerated with one another. The heat generated during the dry sliding and the friction that exists between the two rubbing surfaces caused the agglomeration of the wear debris. The heat released to the particles is due to the rubbing of the two bodies in contact. The friction process of the two bodies operating in contact conditions always involves heat generation and wear of their surfaces. Normal pressure, heat and sliding action velocity are indispensable for wear as they depend on the rubbing process. However, the mechanism of wear involves
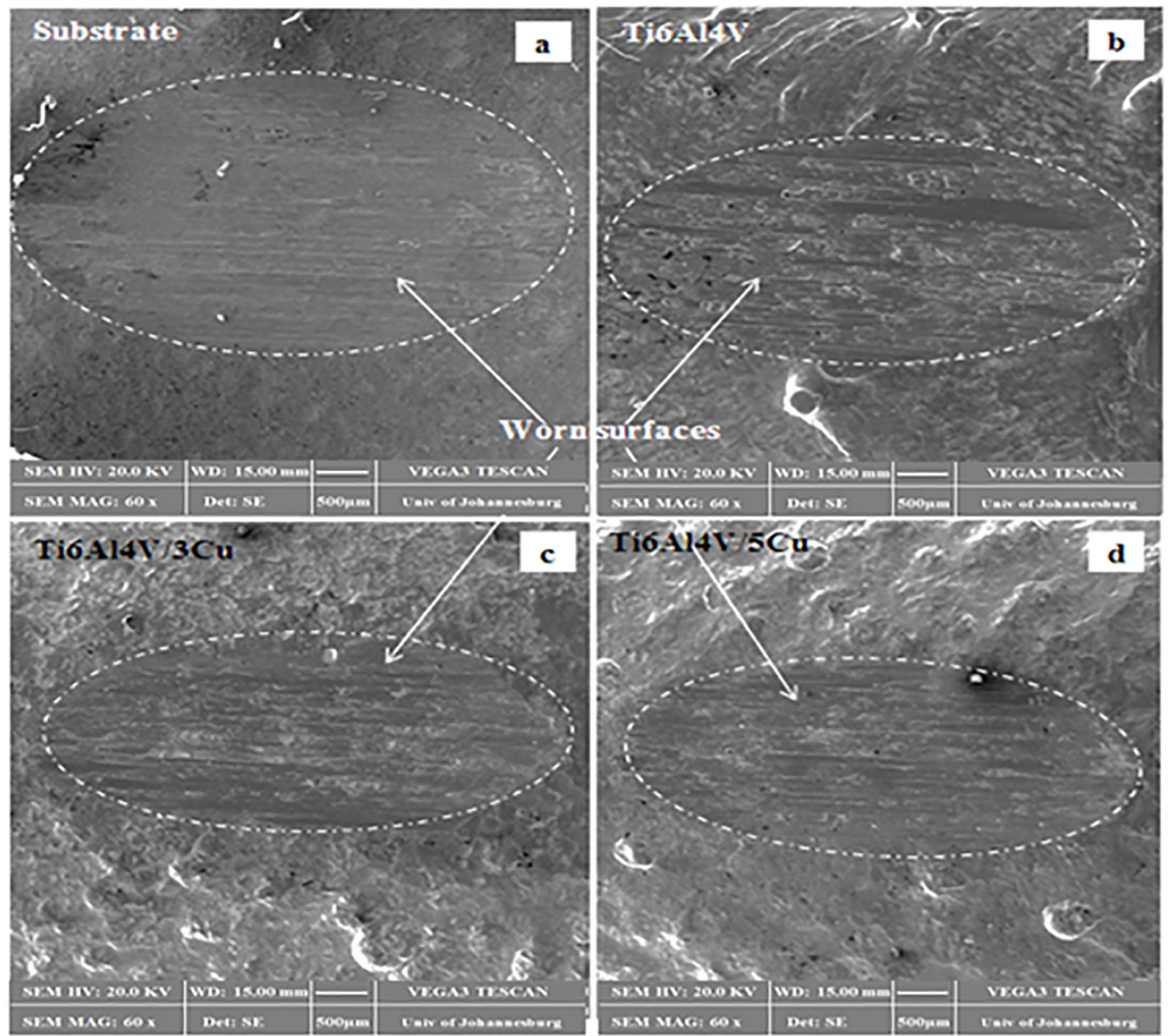

Figure 7. SEM micrographs of the worn surfaces of the alloys focused at low magnification (a) Substrate; (b) Ti6Al4V alloy; (c) Ti6A14V$3 \mathrm{Cu}$; (d) Ti6Al4V-5Cu. 

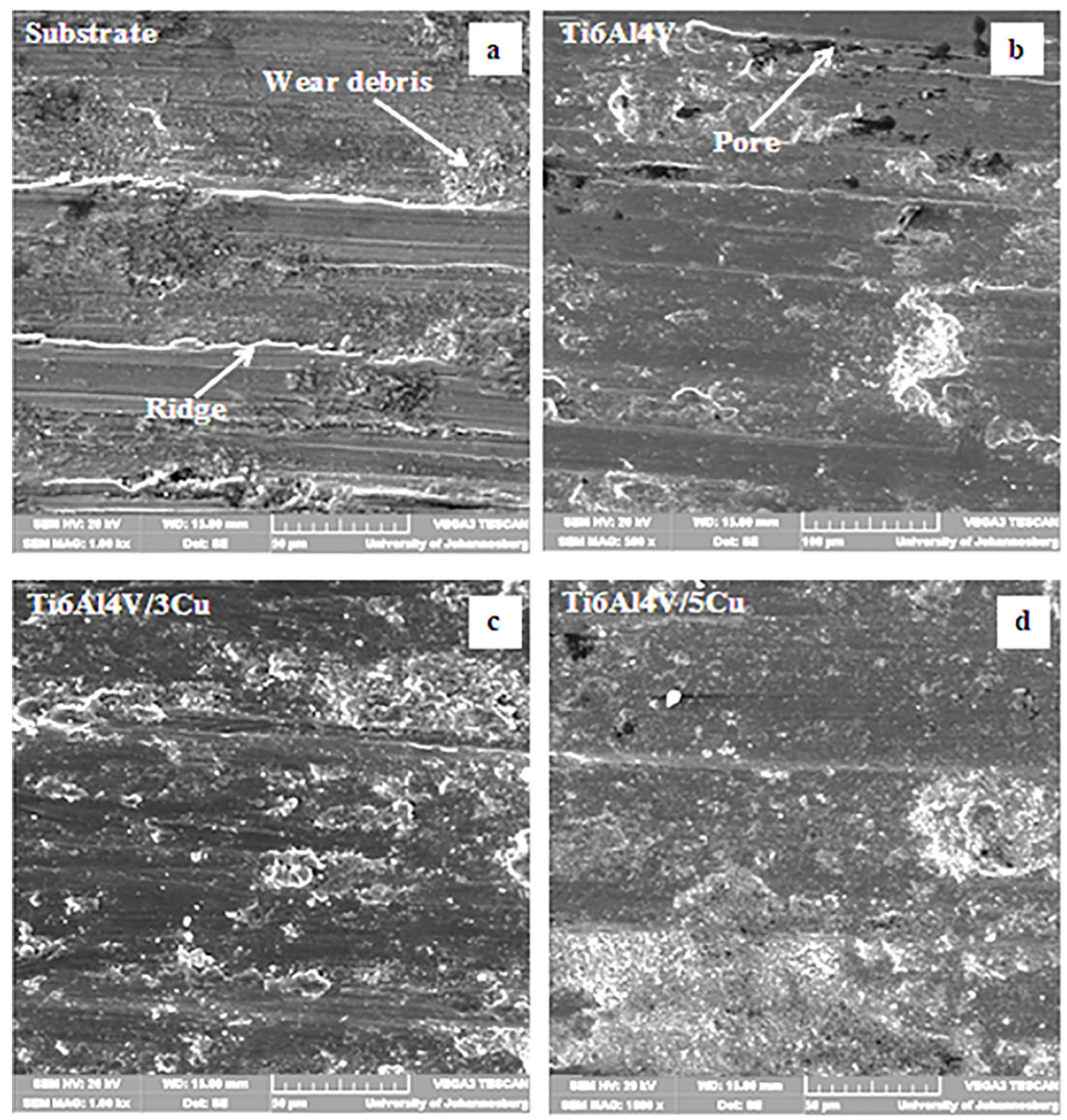

Figure 8. SEM micrographs of the worn surfaces (a) substrate; (b) Ti6Al4V alloy; (c) Ti6A14V-3Cu; and (d) Ti6Al4V-5Cu.

the formation of debris particles in any sliding system and also the agglomeration due to the continuous rubbing of the two bodies. Although, the thermal conductivity $(\mathrm{W} / \mathrm{mK})$ of the tungsten carbide ball is 8 times than that of the Ti6Al4V alloy. The heat generated from the tungsten carbide will be induced into the Ti6Al4V alloy during rubbing. With the small amount of copper added, there is still an impact on the heat generated; and thus has enhanced the properties of the Ti6Al4V-Cu alloy significantly. The total heat power dissipated is equals to the work done by the friction force which is distributed between the two contacting bodies. It can also be stipulated that the substrate and Ti6Al4V surfaces experiences a more significant abrasive wear under the reciprocating sliding condition as compared to Ti6Al4V$3 \mathrm{Cu}$ and Ti6Al4V-5Cu alloys. During the rubbing action, particles of the titanium alloy are transferred and stuck to the tungsten carbide ball due to adhesion as a result of the heat generated. The magnitude of that adhesion depends on the load of $25 \mathrm{~N}$ used, the speed of the rubbing ball and the condition of sliding (dry). Okabe et al. ${ }^{27}$ revealed that the decrease in wear of Ti6Al4V is associated with the presence of $\mathrm{Cu}$ and feasibly the microstructures with the copper eutectoid in the crystal lattices improved the wear resistance as the ductility decreased. Conversely, the wear resistance was further improved within the $\alpha+\beta$ alloy phase which could be responsible for the increased in resistance 
to plastic deformation ${ }^{27}$. The substrate shows the lowest coefficient of friction, COF of 0.017 , followed by the Ti6Al4V with a COF of 0.035 . The large width of wear track of the substrate majorly contributes to its low COF. Sample Z3 of Ti6A14V-5Cu deposited at a laser power of $1200 \mathrm{~W}$ and scanning speed of $0.3 \mathrm{~m} / \mathrm{min}$ was observed to have the highest COF of 0.05 . This nature of rapid decrease of the COF has been reported by Xiong et al. ${ }^{28}$, though; their wear analysis was conducted under distilled water. The loss of wear was calculated using the formular adopted by Qu and Truhan $^{24}$. The width of wear, length of stroke and the wear of depth has been applied to obtain the wear loss. Figure 9 presents the histogram plot of the wear loss.

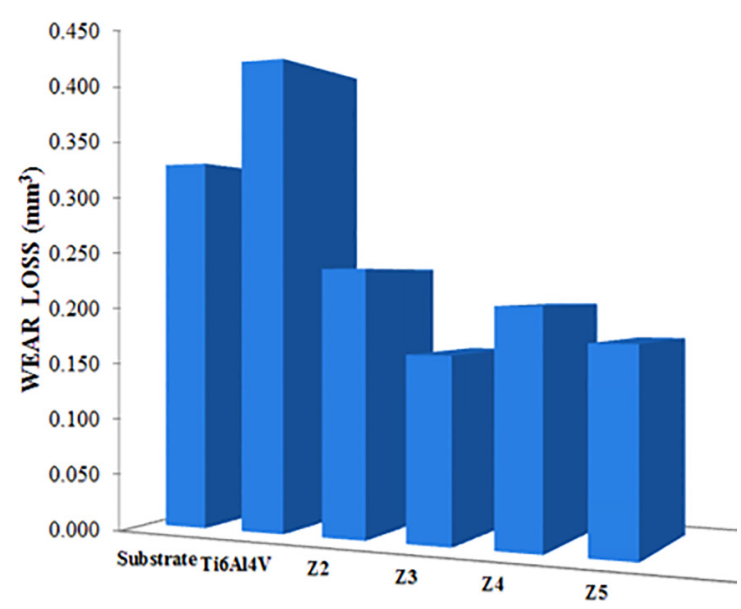

SAMPLES

Figure 9. Histogram plot of wear loss of the substrate, Ti6Al4V, and the Ti6Al4 V-Cu alloys.

It can be detected that samples Z3, Z4 and Z5 of Ti6A14V$5 \mathrm{Cu}$ alloys show the lowest percentage of wear losses of $0.162 \mathrm{~mm}^{3}, 0.204 \mathrm{~mm}^{3}$ and $0.175 \mathrm{~mm}^{3}$ respectively; and fell between $10 \%$ and $14 \%$; but interestingly showed a higher COF as compared to the substrate. On the other hand, sample Z2 of Ti6Al4V-3Cu alloy depicts a percentage of $15 \%$ which is slightly higher and possesses the wear loss of $0.236 \mathrm{~mm}^{3}$. The wear loss of the substrate and the laser deposited Ti6Al4V alloy are $0.332 \mathrm{~mm}^{3}$ and 0.423 $\mathrm{mm}^{3}$ respectively. All the deposited Ti6Al4V-Cu alloys showed an improvement in the wear resistance. Sample Z3 of Ti6Al4V-5Cu alloys deposited with the laser power of $1200 \mathrm{~W}$ and scanning speed of $0.3 \mathrm{~m} / \mathrm{min}$ has the lowest wear loss. It was strangely fascinating that the wear loss of Ti6Al4V alloy is more than that of the substrate. Perhaps, the width and length of the wear scar of the substrate are more than that of the Ti6Al4V alloy but the depth is very much lower. In other word, the depth of wear and the width of wear have a significant role to play in determining the wear loss. The properties of Ti6Al4V-3Cu and Ti6Al4V-5Cu alloys are improved as compared with the substrate and the
Ti6Al4V alloy. Perpetually, the $\mathrm{Cu}$ ions have strengthened the titanium lattices most especially the $\beta$-phases within the body centred cubic region.

\section{Conclusion}

The surface modification of Ti6Al4V alloy was achieved through the addition of $3 \mathrm{wt} \%$ and $5 \mathrm{wt} \%$ of $\mathrm{Cu}$ through laser metal deposition process. The microhardness values of the Ti6Al4V-Cu alloys were improved when compared to the substrate and Ti6Al4V alloys. The coefficient of friction of the substrate and the Ti6Al4V alloy were lower than that of the Ti6Al4V-Cu alloys but the wear losses of both the Ti6Al4V-3Cu and Ti6Al4V-5Cu were greatly improved with a reduced plastic deformation. The substrate shows the widest in wear width and lowest in wear depth. The occurrence was envisaged to be due to the compressive nature of the grain boundaries and the rolled nature of the substrate. Sample $\mathrm{Z} 3$ of Ti6Al4V-5Cu alloys deposited with the laser power of $1200 \mathrm{~W}$ and scanning speed of $0.3 \mathrm{~m} / \mathrm{min}$ has the lowest wear loss. Widmanstätten structures were detected in most of the microstructures and their textures are dependent on the process parameters used. The -Ti phases were found to impede the continuous flow (plastic deformation) of the -phase during cooling due to variation in the slip system.

\section{Acknowledgements}

The authors would to acknowledge the Department of Mechanical Engineering, University of Johannesburg, South Africa and the financial support from the Department of Defense through the research and educational program HBCU/MSI (contract \# W911NF-15-1-0457) under the direct supervision of Dr. Joycelyn S. Harrison (Program Manager, AFOSR Complex Materials and Devices Program).

\section{References}

1. U.S. Congress, Office of Technology Assessment. Advanced Materials by Design-Polymer Matrix Composite, OTA-E-351. Washington: U.S. Government Printing Office; 1988. p. 83-85.

2. Froes HF, Yau TL, Weidenger HG. Titanium, Zirconium and Hafnium. In: Matucha KH, ed. Materials Science and Technology - Structure and Properties of Nonferrous Alloys. Weinheim: VCH Verlag; 1996.

3. Boyer R, Welsch G, Collings EW, eds. Materials Properties Handbook: Titanium Alloys. Materials Park: ASM International; 1994. 1169 p.

4. Gogia AK, Nandy TK, Muraleedharan K, Banerjee D. The effect of heat treatment and niobium content on the room temperature tensile properties and microstructure of $\mathrm{Ti}_{3} \mathrm{Al}-\mathrm{Nb}$ alloys. Material Science and Engineering: A. 1992;159(1):73-86.

5. Sen I, Gopinath K, Datta R, Ramamurty U. Fatigue in Ti-6Al4V-B alloys. Acta Materialia. 2010;58(20):6799-6809. 
6. Okazaki Y, Ito Y, Ito A, Tateishi T. Effect of Alloying Elements on Mechanical Properties of Titanium Alloys for Medical Implants. Materials Transactions, JIM. 1993;34(12):1217-1222.

7. Tian WH, Nemoto M. Effect of carbon addition on the microstructures and mechanical properties of $\gamma$-TiAl alloys. Intermetallics. 1997;5(3):237-244.

8. Leyens C, Peters M, eds. Titanium and Titanium Alloys, Fundamentals and Applications. Weinheim: Wiley-VCH; 2003.

9. Structural Alloys Handbook. Columbus: Battelle's Columbus Laboratories; 1982.

10. Fu Y, Loh NL, Batchelor AW, Liu D, Zhu X, He J, et al. Improvement in fretting wear and fatigue resistance of Ti-6Al-4V by application of several surface treatments and coatings. Surface and Coatings Technology. 1998;106(2-3):193-197.

11. Subramanian C, Cavallaro G, Winkelman G. Wear maps for titanium nitride coatings deposited on copper and brass with electroless nickel interlayers. Wear. 2000;241(2):228-233.

12. Ohkubo C, Shimura I, Aoki T, Hanatani S, Hosoi T, Hattori M, et al. Wear resistance of experimental Ti-Cu alloys. Biomaterials. 2003;24(20):3377-3381.

13. Al-Fozan SA, Malik AU. Effect of seawater level on corrosion behavior of different alloys. Desalination. 2008;228(1-3):61-67.

14. Al-Muhanna K, Habib K. Marine bio-fouling of different alloys exposed to continuous flowing fresh seawater by electrochemical impedance spectroscopy. Journal of Saudi Chemical Society. 2016;20(4):391-396.

15. Legg M, Yücel MK, Garcia de Carellan I, Kappatos V, Selcuk C, Gan TH. Acoustic methods for biofouling control: A review. Ocean Engineering. 2015;103:237-247.

16. Sherif EM, Ammar HR, Khalil KA. Effects of copper and titanium on the corrosion behavior of newly fabricated nanocrystalline aluminum in natural seawater. Applied Surface Science. 2014;301:142-148.

17. Wikispaces. Biological fouling in sea water coolant heat exchangers. Available from: $<$ http://seawaterfouling.wikispaces. com/home >. Access in: 30/5/2017
18. Copper Development Association. Copper and its Alloys. Available from: <http://www.copperalliance.org.uk/copperand-its-alloys/alloys/coppers $>$. Access in: 30/5/2017

19. Vijayan SR, Santhiyagu P, Ramasamy R, Arivalagan P, Kumar G, Ethiraj K, et al. Seaweeds: A resource for marine bionanotechnology. Enzyme and Microbial Technology. 2016;95:45-57.

20. ASTM International. ASTM E3-11 - Standard Guide for Preparation of Metallographic Specimens. West Conshohocken: ASTM International; 2011.

21. Struers. Application Note Titanium. Available from: $<\mathrm{http} / /$ www.struers.com/resources/elements/12/104827/Application Note_Titanium_English.pdf $>$. Access in: 15/10/2013.

22. ASTM International. ASTM E384 - 11e1 - Standard Test Method for Knoop and Vickers Hardness of Materials. West Conshohocken: ASTM International; 2011.

23. ASTM International. ASTM G133-05 (2016) - Standard Test Method for Linearly Reciprocating Ball-on-Flat Sliding Wear. West Conshohocken: ASTM International; 2016.

24. Qu J, Truhan JJ. An efficient method for accurately determining wear volumes of sliders with non-flat wear scars and compound curvatures. Wear. 2006;261(7-8):849-855.

25. Aoki T, Okafor IC, Watanabe I, Hattori M, Oda Y, Okabe T. Mechanical properties of cast Ti6Al4V-XCu alloys. Journal of Oral Rehabilitation. 2004;31(11):1109-1114.

26. Ma CH, Huang JH, Chen $\mathrm{H}$. Nanohardness of nanocrystalline TiN thin films. Surface and Coatings Technology. 2006;200(1213):3868-3875.

27. Okabe T, Kikuchi M, Ohkubo C, Koike M, Okuno O, Oda Y. The grindability and wear of Ti-Cu alloys for dental applications. JOM. 2004;56(2):46-48.

28. Xiong D, Gao Z, Jin Z. Friction and wear properties of UHMWPE against ion implanted titanium alloy. Surface and Coatings Technology. 2007;201(15):6847-6850. 